\title{
humanidades
}

Revista humanidades

Julio-Diciembre, 2015 • Volumen 5, número 2 • ISSN 2215-3934 • pp. 1-3

\section{Las convergencias entre ciencia, tecnología y desarrollo (Reseña)}

Carvajal Villaplana, Álvaro.

Las convergencias entre ciencia, tecnología y desarrollo.

San José: Editorial Guayacán, 2014. ISBN: 978-9968-16-238-8

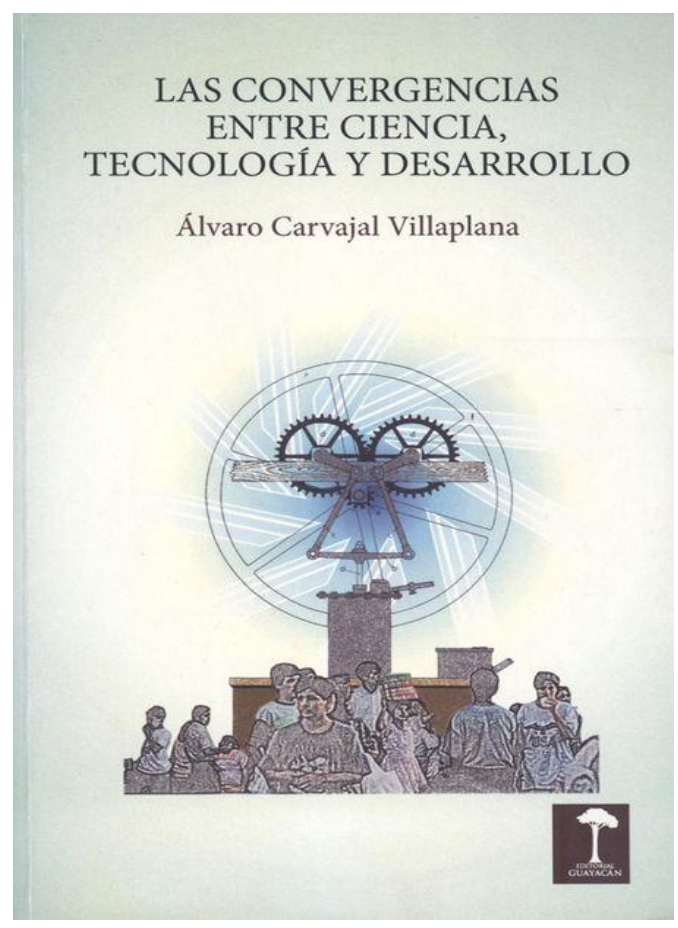

Todos los derechos reservados. Universidad de Costa Rica. Esta revista se encuentra licenciada con Creative Commons 
Esta obra de Carvajal aborda el acuciante tema que implica comprender a la tecnología en su relación con la técnica y la ciencia. El autor, desde un enfoque evolucionista, considera que las relaciones entre estos términos no son meras discontinuidades discursivas, sino una continuidad resemantizada. Así, cada forma de ver dicha relación es histórica, en tal medida, se construye una significación a partir de prácticas culturales propias.

El lector encontrará en el texto una serie de reflexiones sobre la técnica y la tecnología, en las que se debaten argumentos sobre lo que une y distancia a estos conceptos.

Por un lado, se expone que las diferencias aparecen asociadas a la fuente del conocimiento sobre el que se cimientan la creación, el uso y el aprendizaje; que van cambiando con el tiempo. Lo mismo ocurre cuando se discute sobre el argumento de las necesidades, esta tesis, por lo general discontinuista, aduce que la técnica satisface necesidades humanas básicas, mientras que la tecnología crea necesidades superfluas.

Por otro lado, la obra plantea que la tecnología no puede definirse -en primera instancia- como ciencia aplicada. Así pues, el autor aduce que existe una diferencia irreductible entre ciencia y tecnología: La ciencia -en principioestudia lo que existe, la tecnología crea lo que no existe.

De esa forma, se observa un cuestionamiento sobre el conocimiento en sí mismo y su utilidad para el ser humano. Se inicia, entonces, una discusión en la que el conocimiento no implica exclusivamente ciencia; de tal manera, lo que hace diferente a la técnica de la tecnología, a fin de cuentas, es el uso y el acervo de conocimientos (formales, informales y científicos). 
Carvajal, también, reflexiona sobre las diversas formas de relación (progreso contextual) entre ciencia y tecnología, así como entre las nociones de progreso y cambio tecnológico en contraste con la de desarrollo. En tal dirección, el autor posiciona el concepto de capacidades tecnológicas como una necesidad fundamental para entender el desarrollo local de la ciencia y la tecnología. En palabras del autor, la reflexión sobre este concepto se apoya en dos posiciones disciplinares: la economía y la filosofía. Lo anterior es sustentado por la visión económica de Amartya Sen, quien considera las capacidades tecnológicas como condiciones para hacer o ser algo, y la de Ryle, quien emplea el concepto de disposicionalidad: "susceptibilidad o propensión para ser o hacer algo". Se trata, en este caso, de potencialidades, tendencias e inclinaciones: aptitudes para hacer algo, en el marco de la perspectiva de la intencionalidad.

Así las cosas, la necesidad de conectar los alcances en la cotidianidad, es lo que posibilita reflexiones como las encontradas en este texto. Es claro que la ciencia tiende al conocimiento sistematizado mediante el uso de métodos y técnicas, y que la tecnología es el conjunto de habilidades que permiten construir objetos y máquinas para adaptar el medio y satisfacer nuestras necesidades. Se debe, entonces, cuidar que su impacto en la cultura y en el ambiente sea positivo. De esa forma, permitir el desarrollo endógeno de la ciencia y tecnología; por ende, de la innovación, para lograr un desarrollo endógeno a fin al bienestar humano.

Todos los derechos reservados. Universidad de Costa Rica. Esta revista se encuentra licenciada con Creative Commons Reconocimiento-NoComercial-SinObraDerivada 3.0 Costa Rica.

Correo electrónico: humanidades.eeg@ucr.ac.cr / Sitio web: http://revistas.ucr.ac.cr/index.php/humanidades 